九州大学学術情報リポジトリ

Kyushu University Institutional Repository

Flow injection fluorometric determination of ascorbic acid using perylenebisimide-linked nitroxide

Maki, Tomoharu

Department of Applied Chemistry, Graduate School of Engineering, Kyushu University

Soh, Nobuak i

Department of Applied Chemistry, Graduate School of Engineering, Kyushu University

Nakano, Koj i

Department of Applied Chemistry, Graduate School of Engineering, Kyushu University

Imato, Toshihiko

Department of Applied Chemistry, Graduate School of Engineering, Kyushu University

http://hdl. handle. net/2324/25712

出版情報: Talanta. 85 (4)，pp.1730-1733，2011-09-30. Elsevier B.V.

バージョン:

権利関係: (C) 2011 Elsevier B.V. 


\title{
Flow injection fluorometric determination of ascorbic acid using perylenebisimide-linked nitroxide
}

\author{
Tomoharu Maki, Nobuaki Soh, Koji Nakano, Toshihiko Imato* \\ Department of Applied Chemistry, Graduate School of Engineering, Kyushu University, 744 \\ Moto-oka, Nishi-ku, Fukuoka 819-0395, Japan
}

*Corresponding author. Tel./Fax: +81-92-802-2889.

E-mail: imato@cstf.kyushu-u.ac.jp 


\begin{abstract}
A simple and sensitive flow injection fluorometric method for the determination of ascorbic acid is described. Perylenebisimide-linked nitroxide (PBILN) is used as a fluorescent reagent, which permits the selective determination of ascorbic acid. The fluorescence of the perylenebisimide moiety in PBILN is quenched by the nitroxide moiety, which is linked to the perylenebisimide. When a stream of a solution of ascorbic acid is merged with a stream of PBILN, the ascorbic acid reacts with the nitroxide moiety of PBILN to form hydroxylamine, and the fluorescence properties of the perylenebisimide moiety are recovered. As a result, a peak-shaped fluorescence signal is produced, which can be observed by a fluorescence detector located downstream. Under optimized conditions, a good linear relationship between the concentration of ascorbic acid and peak height in the concentration range from 0.5 to $10 \mu \mathrm{mol} \mathrm{L} \mathrm{L}^{-1}$ was found and the detection limit $(\mathrm{S} / \mathrm{N}=3)$ was

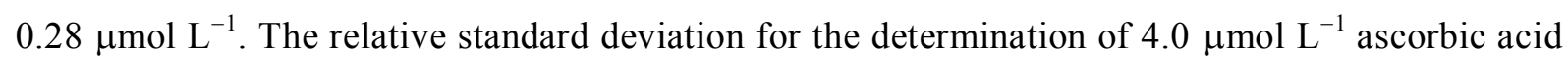
samples was $1.0 \%(n=5)$. The proposed method was applied to the determination of ascorbic acid in several soft drink beverages and the analytical results were in good agreement with those obtained using a conventional method.
\end{abstract}

Keywords: Ascorbic acid; Flow injection analysis; Fluorometric; Nitroxide; Perylene 


\section{Introduction}

Ascorbic acid (vitamin C) plays many important biological roles [1]. It is commonly contained in fruits and vegetables and is also added to food products, because of its antioxidant properties. A wide variety of analytical techniques are available for the determination of ascorbic acid, including as titrimetric analysis, spectroscopy, chromatography, and electroanalysis [2-4]. In process control or quality control of soft drink beverages, a rapid method for its determination is required in order to rapidly analyze it in large quantities of samples. A flow injection analysis (FIA) technique would be ideal and would meet these requirements, due to its simplicity and rapidity. Therefore, a large number of FIA techniques combined with chemiluminescence, electrochemical, spectrophotometric and spectrofluorometric detection methods have been reported [5-10], which are selective for ascorbic acid in the matrix of fruit-derived products. Flow injection fluorometric determination methods for the determination of ascorbic acid using $o$-phenylenediamine (OPDA) and Thionine Blue have been reported [10-13]. Methods using OPDA are based on the oxidation of ascorbic acid by mercury (II) to form a fluorescent quinoxaline derivative $[11,12]$ or on the condensation of ascorbic acid with OPDA [10]. The photooxidation of ascorbic acid by Thionine Blue to form a fluorescent Leucothionine Blue has been utilized for the fluorescence determination of ascorbic acid [13]. Although these methods showed good sensitivity and selectivity for ascorbic acid, OPDA and Thionine Blue are not stable in the presence of oxygen and when subjected to light irradiation. In addition, fluorescence quantum yields of these reaction products are not sufficiently high. Therefore, the use of a compound that is photochemically stable and has a higher fluorescence quantum yield would be highly desirable.

Fluorophore-linked nitroxides represent examples of such compounds. Their fluorescence is quenched by the linked nitroxide moiety [14], but can be recovered when the nitroxide moiety of 
fluorophore-linked nitroxide reacts with certain types of radicals, such as methyl radicals and some reducing agents, such as ascorbic acid. Because of this, fluorophore-linked nitroxides have been used for the detection of reducing agents as well as radicals [15-18]. In this regard, we recently reported on the synthesis and characterization of a perylenebisimide-linked nitroxide that could be used as a hydroxyl radical probe [19]. During our studies of this probe, we confirmed that it was highly reactive with respect to ascorbic acid and emitted a strong fluorescence due to the high quantum yield of the perylenebisimide moiety. The fluorescence is quenched due to the quenching effect of the nitroxide moiety linked to the probe, which has a high reactivity for ascorbic acid. When ascorbic acid reacts with the nitroxide moiety, the quenching effect is released, thus creating a high fluorescence. This indicates that the probe is a promising reagent for the rapid and sensitive fluorometric determination of ascorbic acid by combining it with an FIA technique.

In this paper, we describe a flow injection fluorometric method for the determination of ascorbic acid using perylenebisimide-linked nitroxide as a reagent after determination of the optimum conditions, such as reaction time, coil length, flow rate and sample volume. The proposed method was successfully applied to the determination of ascorbic acid in some commercial soft drink beverages.

\section{Experimental}

\subsection{Reagents and preparation of solutions}

Ascorbic acid was purchased from Kishida Chemical Co., Ltd. (Japan). Stabilizer free tetrahydrofuran (THF) and acetic acid were purchased from Wako Pure Chemical Industries Ltd. (Japan). Perylenebisimide-linked nitroxide (PBILN) was prepared, as described in our previous 
paper [19]. All other reagents were of the reagent grade and were used without further purification.

A standard stock solution of ascorbic acid $\left(10 \mathrm{mmol} \mathrm{L}^{-1}\right)$ was prepared daily by dissolving $88 \mathrm{mg}$ of ascorbic acid in $50 \mathrm{~mL}$ of a $0.1 \mathrm{~mol} \mathrm{~L}^{-1}$ acetic acid aqueous solution. Working standard solutions of ascorbic acid were prepared by appropriate dilution of the stock standard solution with a $0.1 \mathrm{~mol} \mathrm{~L}^{-1}$ acetic acid solution. A stock solution of perylenebisimide-linked nitroxide $(0.5 \mathrm{mmol}$ $\mathrm{L}^{-1}$ ) was prepared by dissolving an appropriate amount of perylenebisimide-linked nitroxide in THF.

\subsection{Apparatus}

An HPLC pump (Jasco, PU-2080) and a double plunger pump (Aqualab, PE-230) were used. PTFE tubing (0.50 mm i.d.) was used for construction of the manifold. An injector (Rheodyne, 7725i) with a sample loop (100 $\mu \mathrm{L}$, PEEK tubing) was used for injecting sample solutions. A fluorescence detector (Hitachi, F-1050) was used for detecting the fluorescence signal. An A/D converter (LAsoft, ADC44) was used to convert the fluorescence signal from the fluorescence detector to a digital signal for storage on a PC.

\subsection{Procedure}

The FIA system was comprised of two pumps $\left(\mathrm{P}_{1}, \mathrm{P}_{2}\right)$, the injector $(\mathrm{V})$, a reaction coil (RC), the fluorescence detector (D), the A/D converter (C), and the computer (PC) as shown in Fig. 1. A sample solution of ascorbic acid was injected into a carrier stream $\left(20 \mathrm{mmol} \mathrm{L}^{-1} \mathrm{HCl} / \mathrm{THF}(1 / 1\right.$, $\mathrm{v} / \mathrm{v})$ ) and merged with a $1.0 \mu \mathrm{mol} \mathrm{L} \mathrm{L}^{-1}$ PBILN solution prepared with the same matrix as the carrier stream. The mixed solution was introduced into the reaction coil $(20 \mathrm{~m} \times 0.50 \mathrm{~mm}$ i.d. $)$ and the change in fluorescence of the reaction product was measured with the fluorescence detector at an 
excitation wavelength of $490 \mathrm{~nm}$ and a fluorescence wavelength of $537 \mathrm{~nm}$.

\section{Results and discussion}

\subsection{Fluorescence properties in batch system}

Before using PBILN for the reagent solution of the FIA system, its reactivity with ascorbic acid was investigated in a batch system. Fig. 2 shows the fluorescence spectra of PBILN before and after reaction with ascorbic acid in a $20 \mathrm{mmol} \mathrm{L}^{-1} \mathrm{HCl} / \mathrm{THF}(1 / 1, \mathrm{v} / \mathrm{v})$ solution. THF was used as a co-solvent due to the low solubility of PBILN in water. As shown in Fig. 2(b), the PBILN solution itself showed a relatively low fluorescence, as shown in Fig. 2(a). This low fluorescence intensity of PBILN is due to the fact that the fluorescence of the perylenebisimide moiety is quenched by the nitroxide moiety. When a $1 \mu \mathrm{mol} \mathrm{L}{ }^{-1}$ reagent solution was mixed with a $100 \mu \mathrm{mol}$

$\mathrm{L}^{-1}$ ascorbic acid solution, a strong fluorescence with a fluorescence maximum at a wavelength of $537 \mathrm{~nm}$ is observed. This result indicates that the nitroxide moiety of PBILN is converted to hydroxylamine when the ascorbic acid solution is added to the PBILN solution. This observation, therefore, confirms that PBILN is applicable for the sensitive determination of ascorbic acid.

\subsection{Optimization of the FIA conditions}

In order to optimize the FIA conditions, the effect of FIA parameters, such as flow rate, reaction coil length and sample volume were investigated using a $4.0 \mu \mathrm{mol} \mathrm{L} \mathrm{L}^{-1}$ ascorbic acid standard solution. The effect of the flow rate of the two streams, the carrier and PBILN solutions, on the fluorescence signal was investigated by changing their flow rates from 0.3 to $0.9 \mathrm{~mL} \mathrm{~min}$. As can be seen in Fig. 3(A), when the flow rate was increased from 0.3 to $0.9 \mathrm{~mL} \mathrm{~min}^{-1}$, the peak 
height of the fluorescence signal decreased. Therefore, a flow rate of $0.3 \mathrm{~mL} \mathrm{~min}^{-1}$ was used, as a compromise between sensitivity and analytical throughput.

Fig. 3(B) shows the effect of reaction coil length on peak height when the length of the reaction coil is varied from 2 to $30 \mathrm{~m}$. The average time for the reaction of ascorbic acid with PBILN in the reaction coil is estimated to be from 0.65 to $9.8 \mathrm{~min}$ for the present coil length and flow rate. The peak height gradually increases with increasing coil length up to about $20 \mathrm{~m}$ and then reaches a plateau. This result indicates that a $20 \mathrm{~m}$ long reaction coil allows sufficient time for ascorbic acid to react completely with PBILN. Therefore, a $20 \mathrm{~m}$ long reaction coil was used for subsequent experiments.

The effect of sample injection volume was investigated by changing the volume of the sample loop from 5 to $200 \mu \mathrm{L}$. As shown in Fig. 3(C), the peak height gradually increases with increasing sample volume up to $100 \mu \mathrm{L}$ and then reaches a plateau. This indicates that the dispersion of the sample gave in the reaction coil is likely negligibly small when the sample volume is larger than $100 \mu \mathrm{L}$ under the present flow conditions. Therefore, a sample volume of 100 $\mu \mathrm{L}$ was used as the volume.

\subsection{Calibration curve}

The calibration curve for the determination of ascorbic acid was obtained using the standard solutions under the optimized conditions outlined above. Flow signals obtained for the calibration curve are shown in Fig. 4(A), where different concentrations of standard ascorbic acid solution from 0.5 to $10 \mu \mathrm{mol} \mathrm{L}{ }^{-1}$ were injected three times each for the same concentration sample. The baseline of the FIA gram was stable and the fluctuation was less than $10 \mathrm{mV}$, although the small bias of fluorescence intensity from the fluorophore itself was about $100 \mathrm{mV}$. As shown in Fig. 4(B), 
the calibration curve was linear for ascorbic acid, in the concentration range from 0.5 to $10 \mu \mathrm{mol}$ $\mathrm{L}^{-1}$, with a correlation coefficient of 0.9987 . The relative standard deviation was $1.0 \%(n=5)$ for the determination of the $4.0 \mu \mathrm{mol} \mathrm{L}{ }^{-1}$ ascorbic acid solution. The detection limit, defined as $\mathrm{S} / \mathrm{N}=$ 3, was $0.28 \mu \mathrm{mol} \mathrm{L}{ }^{-1}$.

\subsection{Interference investigation}

In order to apply the proposed method to the determination of ascorbic acid in commercially produced beverages, the influence of some possible interfering compounds that are typically found in fruit juices and soft drinks was investigated. The compounds and their concentration range shown in Table 1 were selected for investigation of the interference against the present method. A mixed solution containing ascorbic acid at a constant concentration of $4.0 \mu \mathrm{mol} \mathrm{L}-1$ and substance to be examined, at concentration of up to $1 \mathrm{mmol} \mathrm{L}^{-1}$, was injected into the carrier stream. The error due to the potentially interfering substances in the determination of ascorbic acid was estimated by comparing the signal obtained for the mixed solution with that obtained for the $4.0 \mu \mathrm{mol} \mathrm{L} \mathrm{L}^{-1}$ ascorbic acid without the interfering substance. The errors calculated from the peak heights for the ascorbic acid solution with and without the substances are listed for each substance in Table 1. The presence of sucrose, glucose, fructose, maleic acid, succinic acid and sorbic acid cause negligibly small interferences in the determination of ascorbic acid. Interestingly, negative interferences from malic acid, malonic acid and citric acid were observed, although these substances do not cause an increase in fluorescence when they were mixed with the PBILN solution. This is because they do not react with the nitroxide moiety of PBILN to generate fluorescence. The reason for the interference by malic acid, malonic acid and citric acid is not clear at this stage. For applications of the proposed method for the determination of ascorbic acid in fruit 
juices and soft drinks, since the presence of such substances are relatively low compared with ascorbic acid, the extent of their interference would be negligibly small. Indeed, as shown in the next section, the method was successfully applied to the determination of ascorbic acid in fruit juices and soft drinks.

\subsection{Application to real samples}

The proposed method was applied to the determination of ascorbic acid in commercial beverages. Two fruit juice and two soft drink samples were used as test materials. The samples were diluted to an appropriate concentration with deionized water. The results obtained using the proposed method are shown in Table 2 together with those obtained using a reference 2,6-dichlorophenolindophenol method [20]. The data in Table 2 indicate that the ascorbic acid contents determined by the present method are in good agreement with those obtained by the conventional method.

\section{Conclusions}

A fluorescence probe, perylenebisimide-linked nitroxide, was applied to the flow injection fluorometric determination of ascorbic acid by optimizing the flow conditions with respect to sensitivity and analytical throughput. Under the optimized conditions, a good linear relationship between the concentration of ascorbic acid and the peak height of fluorescence intensity was observed with a lower detection limit of $0.28 \mu \mathrm{mol} \mathrm{L}^{-1}$. Even though the proposed method requires relatively long reaction time (ca. $6 \mathrm{~min}$ ) for completion of the reaction of ascorbic acid with PBILN, the sample throughput was ca. $10 \mathrm{~h}^{-1}$, the proposed method showed high sensitivity and 
good reproducibility. Since one of the advantages of the flow injection analysis is that a complete reaction in the reaction coil is not necessary. As a result, sample throughput can be increased to 60 $\mathrm{h}^{-1}$ by using a shorter reaction time (ca. $1 \mathrm{~min}$ ), if a decrease in sensitivity of one-third can be accepted. The proposed method was successfully applied to the determination of ascorbic acid in some commercial beverages. Considering further applications, the excellent fluorescence properties of the perylenebisimide would be useful for the construction of a compact microfluidic analytical system.

\section{Acknowledgement}

This work was supported by a Grant-in-Aid for the Global COE Program, "Science for Future Molecular Systems" from the Ministry of Education, Culture, Sports, Science and Technology, Japan, and Research Fellowships of the Japan Society for the Promotion of Science (JSPS) for Young Scientists. 


\section{References}

[1] S. Englard, S. Seifter, Annu. Rev. Nutr. 6 (1986) 365-406.

[2] P.W. Washko, R.W. Welch, K.R. Dhariwal, Y.H. Wang, M. Levine, Anal. Biochem. 204 (1992) $1-14$

[3] S.P. Arya, M. Mahajan, P. Jain, Anal. Chim. Acta 417 (2000) 1-14.

[4] O.A. Zaporozhets, E.A. Krushinskaya, J. Anal. Chem. 57 (2002) 286-297.

[5] M.C. Yebra-Biurrun, Talanta 52 (2000) 367-383.

[6] Y.J. Ma, M. Zhou, X.Y. Jin, B.Z. Zhang, H. Chen, N.Y. Guo, Anal. Chim. Acta 464 (2002) 289-293.

[7] J.R.L. Guerreiro, A.H. Kamel, M.G.F. Sales, Food Chem. 120 (2010) 934-939.

[8] T. Takayanagi, M. Nishiuchi, M. Ousaka, M. Oshima, S. Motomizu, Talanta 79 (2009) 1055-1060.

[9] M. Ozyurek, K. Guclu, B. Bektasoglu, R. Apak, Anal. Chim. Acta 588 (2007) 88-95.

[10] T. Perez-Ruiz, C. Martinez-Lozano, V. Tomas, J. Fenol, Analyst 126 (2001) 1436-1439.

[11] H.K. Chung, J.D. Ingle Jr., Talanta 38 (1991) 355-357.

[12] H. Huang, R. Cai, Y. Du, Y. Zeng, Anal. Chim. Acta 309 (1995) 271-275.

[13 P re - ui , Mart ne -Lo ano, om s, C. Sidrach, Analyst 122 (1997) 115-118.

[14] N.V. Blough, D.J. Simpson, J. Am. Chem. Soc. 110 (1988) 1915-1917.

[15] E. Lozinsky, V.V. Martin, T.A. Berezina, A.I. Shames, A.L. Weis, G.I. Likhtenshtein, J. Biochem. Biophys. Methods 38 (1999) 29-42.

[16] G.G. Borisenko, I. Martin, Q. Zhao, A.A. Amoscato, Y.Y. Tyurina, V.E. Kagan, J. Biol. Chem. 279 (2004) 23453-23462.

[17] M. Jia, Y. Tang, Y. Lam, S.A. Green, N.V. Blough, Anal. Chem. 81 (2009) 8033-8040. 
[18] J.L. Chen, S.J. Zhuo, Y.Q. Wu, F. Fang, L. Li, C.Q. Zhu, Spectroc. Acta Pt. A-Molec. Biomolec. Spectr. 63 (2006) 438-443.

[19] T. Maki, N. Soh, T. Fukaminato, H. Nakajima, K. Nakano, T. Imato, Anal. Chim. Acta 639 (2009) 78-82.

[20] S.H.R. Davies, S.J. Masten, Anal. Chim. Acta 248 (1991) 225-227. 


\section{Figure captions}

Fig. 1. FIA system for the determination of ascorbic acid. RS: $1 \mu \mathrm{mol} \mathrm{L} \mathrm{L}^{-1}$ perylenebisimide-linked nitroxide (reagent) solution in $20 \mathrm{mmol} \mathrm{L}{ }^{-1} \mathrm{HCl} / \mathrm{THF}(1 / 1, \mathrm{v} / \mathrm{v}), \mathrm{CS}$ : carrier solution of $20 \mathrm{mmol}$ $\mathrm{L}^{-1} \mathrm{HCl} / \mathrm{THF}(1 / 1, \mathrm{v} / \mathrm{v}), \mathrm{P}_{1}, \mathrm{P}_{2}$ : pumps, V: injector with sample loop $(100 \mu \mathrm{L}), \mathrm{RC}$ : reaction coil (0.50 mm i.d.), D: fluorescence detector, C: A/D converter, PC: computer.

Fig. 2. Fluorescence spectra of the perylenebisimide-linked nitroxide (PBILN) $\left(1 \mu \mathrm{mol} \mathrm{L}{ }^{-1}\right)$ in 20 mmol L ${ }^{-1} \mathrm{HCl} / \mathrm{THF}(1 / 1, \mathrm{v} / \mathrm{v})$ solution with excitation at $490 \mathrm{~nm}$. (a) Fluorescence spectrum of PBILN before the addition of ascorbic acid, (b) fluorescence spectra of PBILN after the addition of an ascorbic acid solution $\left(100 \mu \mathrm{mol} \mathrm{L} \mathrm{L}^{-1}\right)$.

Fig. 3. Optimization of flow conditions for the determination of ascorbic acid. (A) Effect of flow rate. coil length: $10 \mathrm{~m}$, sample volume: $50 \mu \mathrm{L}$. (B) Effect of reaction coil length. flow rate: $0.5 \mathrm{~mL}$ $\min ^{-1}$, sample volume: $50 \mu \mathrm{L}$. (C) Effect of sample volume. coil length: $10 \mathrm{~m}$, flow rate: $0.5 \mathrm{~mL}$ $\min ^{-1}$. Concentration of ascorbic acid was $4.0 \mu \mathrm{mol} \mathrm{L}{ }^{-1}$. RS and CS are the same as in Fig. 1.

Fig. 4. (A) Flow signals for the determination of ascorbic acid. Concentration of the standard solution of ascorbic acid; (a) $0.5 \mu \mathrm{mol} \mathrm{L}{ }^{-1}$, (b) $1.0 \mu \mathrm{mol} \mathrm{L}{ }^{-1}$, (c) $2.0 \mu \mathrm{mol} \mathrm{L}^{-1}$, (d) $4.0 \mu \mathrm{mol} \mathrm{L}^{-1}$, (e) $6.0 \mu \mathrm{mol} \mathrm{L} \mathrm{L}^{-1}$, (f) $8.0 \mu \mathrm{mol} \mathrm{L} \mathrm{L}^{-1}$, (g) $10.0 \mu \mathrm{mol} \mathrm{L}{ }^{-1}$. Flow condition; flow rate: $0.5 \mathrm{~mL} \mathrm{~min}^{-1}$, sample volume: $100 \mu \mathrm{L}$, reaction coil length: $20 \mathrm{~m}$. (B) Calibration curve for the determination of ascorbic acid. RS and CS are the same as in Fig. 1. 


\section{Table 1}

Effect of some potentially interfering substances on the determination of ascorbic acid ${ }^{\text {a }}$

\begin{tabular}{lll}
\hline Species added & Added concentration $\left(\mathrm{mmol} \mathrm{L}^{-1}\right)$ & Error $^{\mathrm{b}}(\%)$ \\
\hline Sucrose & 1.0 & +0.2 \\
Glucose & 1.0 & -0.5 \\
Fructose & 1.0 & -3 \\
Maleic acid & 1.0 & -0.8 \\
Succinic acid & 1.0 & -4 \\
Sorbic acid & 1.0 & -1 \\
Malic acid & 1.0 & -27 \\
& 0.5 & +0.8 \\
Malonic acid & 1.0 & -38 \\
Citric acid & 0.1 & +0.6 \\
& 1.0 & -42 \\
\hline
\end{tabular}

${ }^{a}$ Ascorbic acid concentration $4 \mu \mathrm{mol} \mathrm{L}{ }^{-1}$.

${ }^{\text {b }}$ Calculated by $\left(\mathrm{H}_{\mathrm{a}+\mathrm{s}}-\mathrm{H}_{\mathrm{a}}\right) / \mathrm{H}_{\mathrm{a}} \cdot \mathrm{H}_{\mathrm{a}+\mathrm{s}}$ and $\mathrm{H}_{\mathrm{a}}$ denote the peak height obtained for the ascorbic acid solution containing the substance and that obtained for the ascorbic acid without the substance. 


\section{Table 2}

Analytical results for the determination of ascorbic acid in commercial beverages by the proposed method and the standard method

\begin{tabular}{lll}
\hline \multirow{2}{*}{ Sample } & \multicolumn{2}{c}{${\text { Found }\left(\mathrm{mmol} \mathrm{L}^{-1}\right)}^{\circ}$} \\
\cline { 2 - 3 } & Proposed method $^{\mathrm{a}}$ & Standard method $^{\mathrm{b}}$ \\
\hline Fruit juice A & $1.01 \pm 0.02$ & 1.02 \\
Fruit juice B & $1.59 \pm 0.01$ & 1.49 \\
Soft drink A & $5.88 \pm 0.01$ & 5.42 \\
Soft drink B & $35.7 \pm 0.87$ & 35.3 \\
\hline
\end{tabular}

${ }^{\text {a }}$ Average \pm standard deviation $(n=3)$.

${ }^{\mathrm{b}}$ Values determined by the standard method according to Ref. 20. 


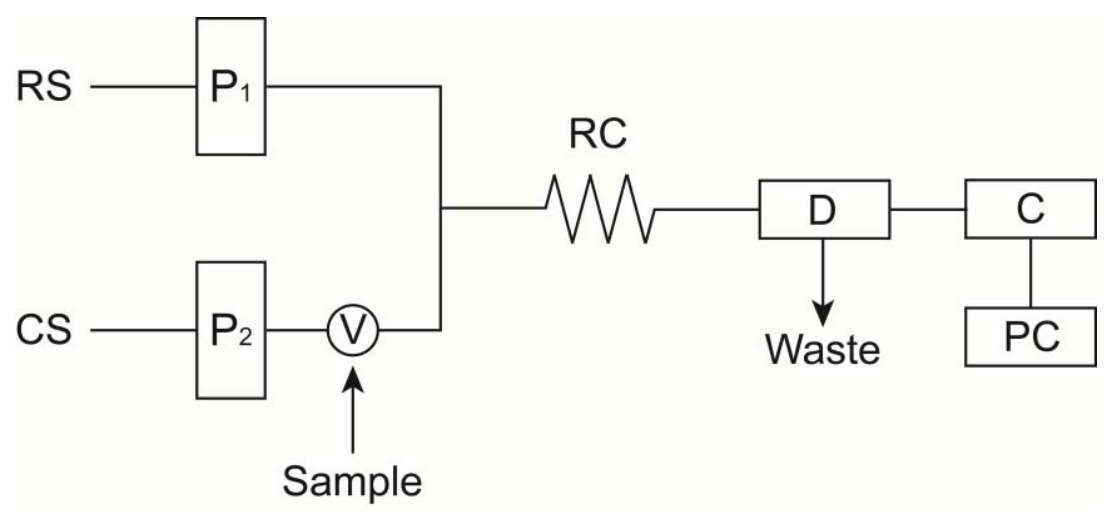

Fig. 1 


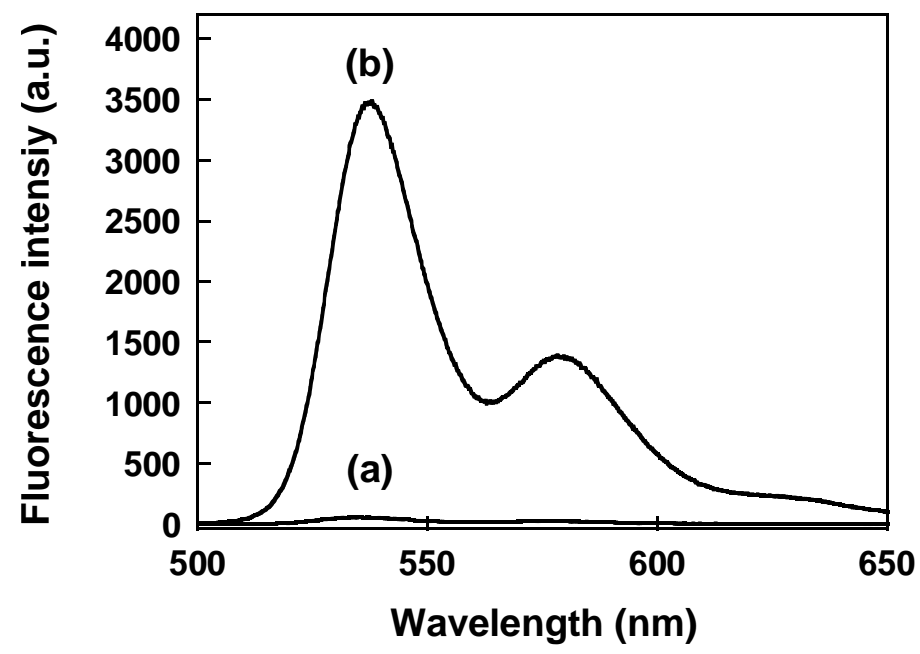

Fig. 2 
(A)

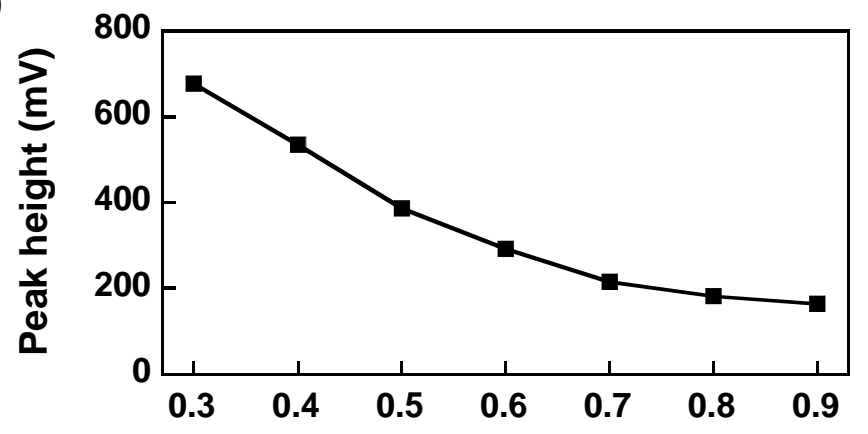

Flow rate $\left(\mathrm{mL} \mathrm{min}^{-1}\right)$

(B) Reaction time (min)

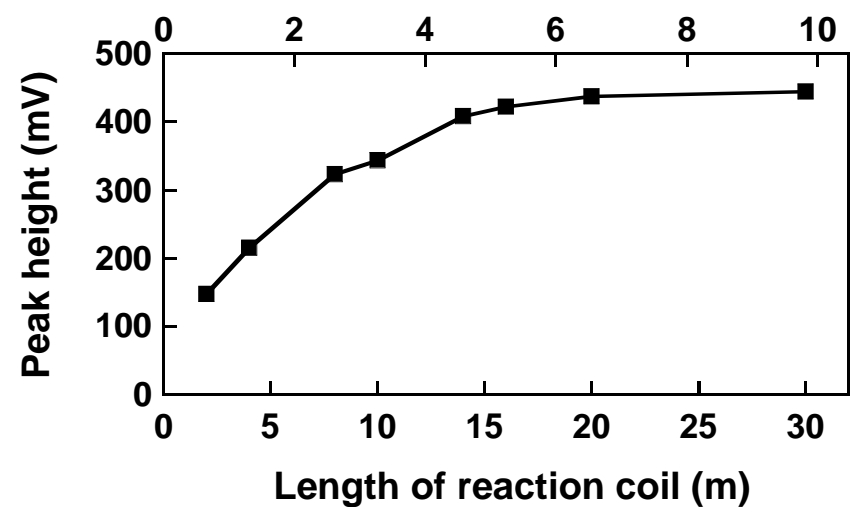

(C)

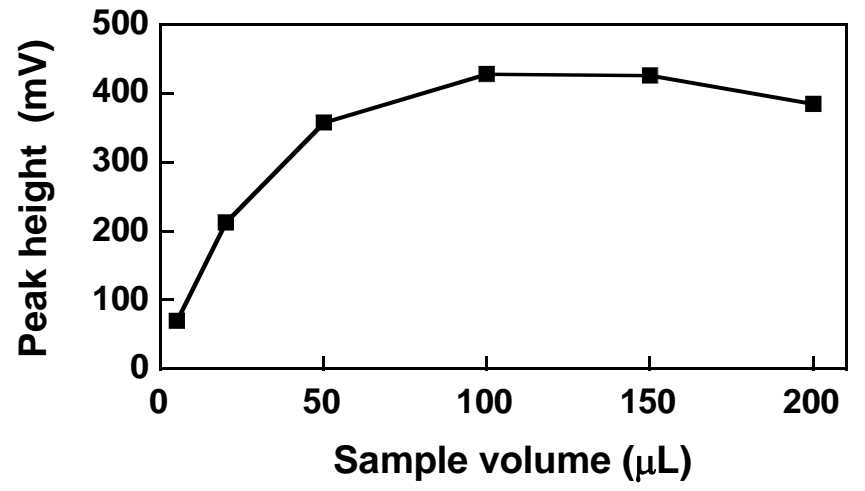

Fig. 3 
(A)

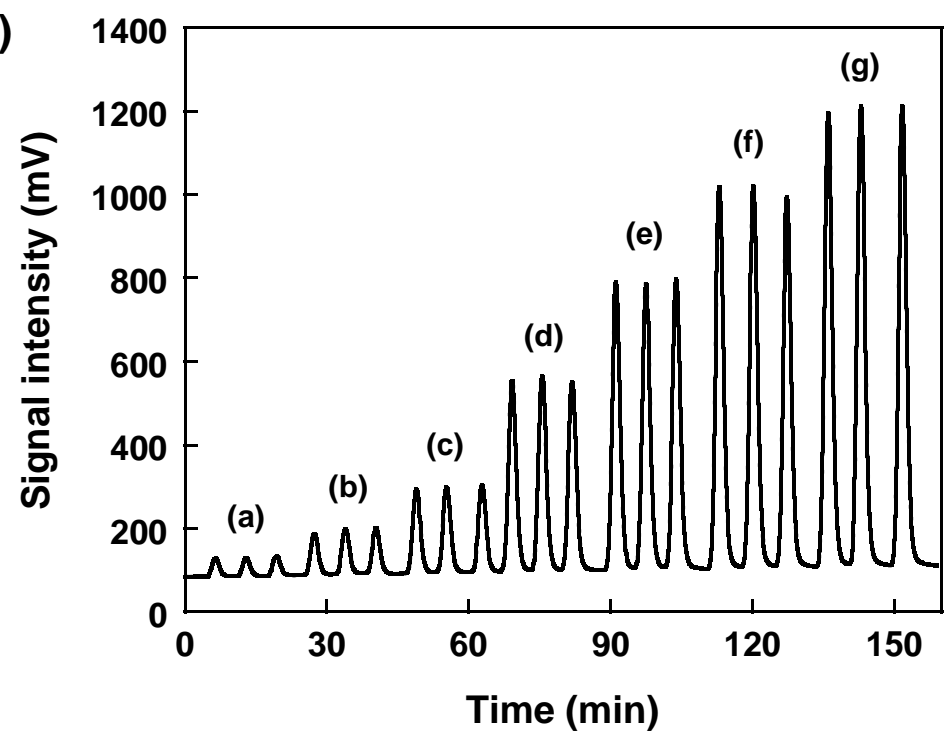

(B)

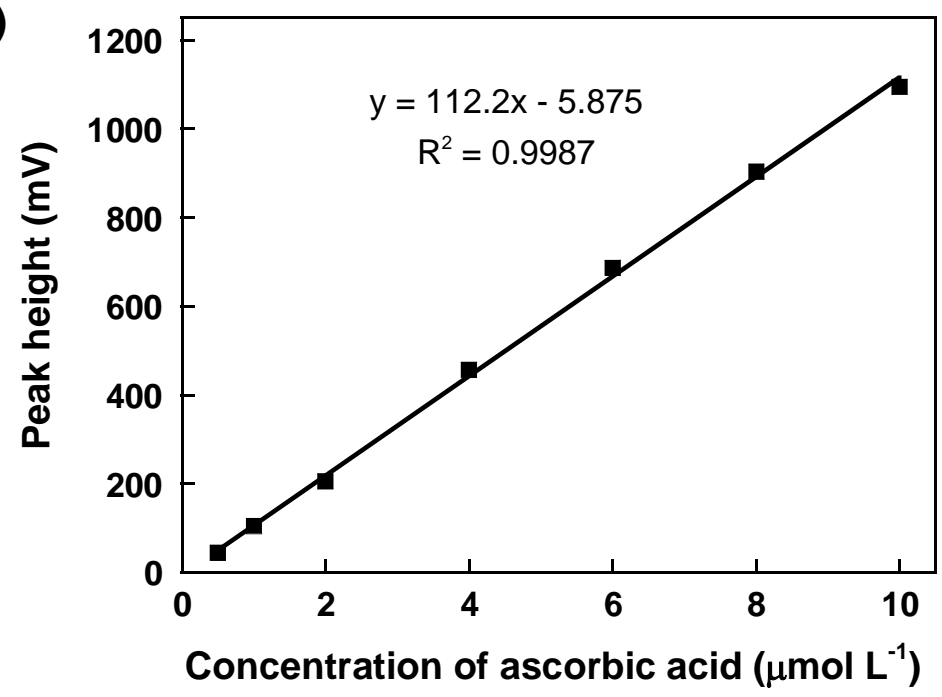

Fig. 4 